\title{
Relations of Infinite Spaces in Full Voids and Constitution of Total Energies and their Effect on Matter
}

\author{
Mohamed Daris* \\ Department of Physics, University of Sciences, Morocco
}

\author{
*Corresponding Author: Mohamed Daris, Department of Physics, University of Sciences, Morocco
}

\begin{abstract}
I did this work and specifically this project to make a simple argument to show There is something else behind the light is its new speed input has it Energy and bring out a new relationship of light and that this new relationship will Change all the old settings that exists and has a ratio of approach need for the community Because the community is always looking for the science and new relationship and my Project will improve the approach by providing the needs of the community and ca has a consequence Positive total return and hence global performance level Physical and especially in the Field of the speed of light everybody knowing Search the reality around any relationships exist and settings that are either hardware Equipment or not and my effort is based on the hardware side for a light and Calculation that will give us the truth that is behind the light and there is something else that Are hidden that the experience will give us. All that man will find it or go get it is found in our brain just Point the finger on the right path to find the result.
\end{abstract}

\section{INTRODUCTION}

I have introduced into these file new concepts concerning new concepts on the mathematical development of full voids in infinite

Spaces and consequently I have brought out a new concept is the energy of this infinite space and its speed and connecting them with

The speed of light and energy and light.

The concept is to better understand the notion of energy constituting in the emptiness of infinite spaces in my theorem I try to summarize

The Concept and relations that make up of this.

\section{DISCUSSION}

So here is my statement for the proposal with graphics and all this in the page As follows:

It was as complete theorem the fundamental relationship of the following universe:

] A [ $=] 1[$;

The new benchmark based on 1 is as follows:

$\mathrm{A}=1 \quad ;$

General stable relationship (universal equilibrium relationship).

It was as a result of the mark:

$\mathrm{A}=\mathrm{B} * \mathrm{C} * \mathrm{D} / \mathrm{Z}^{2}$

So we have:

$$
B * C^{*} D / Z^{2}=1^{\prime}
$$

And:

$\mathbf{A}=\mathbf{1}$;

The question is what is $B * C * D / Z^{2}=A=1 \neq 1 ? ;$

Mathematics can be a physical side ensures this relationship as follows: 
$\mathrm{A}=\mathrm{E} ; \quad$ and $\quad 1^{\prime}=\mathrm{C}^{\prime}$;

It was as you know:

$\mathrm{E}=\mathrm{B}^{*} \mathrm{C}^{*} \mathrm{D} / \mathrm{Z}^{2} \quad ;$

Emphasis $\quad \mathrm{B} * \mathrm{D}=\mathrm{M} \quad$;

The relationship becomes:

$\mathrm{E}=\mathrm{M} * \mathrm{C} / \mathrm{Z}^{2}$

It was as a result:

$\mathrm{C} / \mathrm{Z}^{2}=\mathrm{C}^{\prime}=1^{\prime} \quad ; \quad \mathrm{Z}=$ square $\operatorname{root}\left(\mathrm{C}^{\prime} \mathrm{C}^{\prime}\right)=11^{\prime} \quad ;$

So we have: $\quad E / M=C^{\prime}$;

Consequence:

$\mathrm{E}=\mathrm{C}^{\prime} \mathrm{M}$;

Equation represents the interaction between energy and mass;

And this is the fundamental relationship of the universe.

Alternatively we have:

$\mathrm{E}=1^{\prime}=\mathrm{C}^{\prime} \mathrm{M}$;

$1^{\prime}=\mathrm{C}^{\prime} \mathrm{M} \quad$ equivalence $\quad 1^{\prime} / \mathrm{C}^{\prime}=\mathrm{M} \quad$;

$1^{\prime} / \mathrm{C}^{\prime}=1 \quad$;

Consequence of this relationship was always:

$1=1$

So the end result of this equation is the interval:

] E, M [

] $1,1^{\prime}[$

Relationship of absolute gaps in the full space:

Was : $\mathbf{E}=\mathbf{M}$ result was the result $\mathbf{E}^{\prime}=\mathbf{M}^{\prime}$

So we can solve the following range:

] $1^{\mathrm{e}}, 1^{\mathrm{e}}, 1^{\mathrm{m}}, 1^{\mathrm{m}}$ [

The equations needed for this range are as follows:

$1^{\mathrm{E}} * 1^{\mathrm{M}},=1^{\mathrm{E}} \mathrm{M}$,

$1^{\mathrm{E}} * 1^{\mathrm{M}}=1^{\mathrm{EM}}$

$1^{\mathrm{E}} * 1^{\mathrm{M}},-1^{\mathrm{E}, \mathrm{M}},=0$

$1^{\mathrm{E}} * 1^{\mathrm{M}}-1^{\mathrm{EM}}=0$

1 and 2 are equal so we will write:

$\left(1^{\mathrm{E} *} 1^{\mathrm{M}}\right)-1^{\mathrm{EM}}=\left(1^{\mathrm{E}} * 1^{\mathrm{M}}\right)-1^{\mathrm{E}}, \mathrm{M}$,

$\left(1^{\mathrm{E}} * 1^{\mathrm{M}}\right)-\left(1^{\mathrm{E}} * 1^{\mathrm{M}}\right)=1^{\mathrm{EM}}-1^{\mathrm{E}^{\prime} \mathrm{M}}$

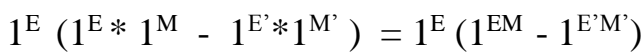

$1^{\mathrm{E} *}\left(1^{\mathrm{E} *} 1^{\mathrm{M}}\right)-1^{\mathrm{E} *}\left(1^{\mathrm{E} *} * 1^{\mathrm{M}^{\prime}}\right)=1^{\mathrm{EM}} * 1^{\mathrm{E}}-1^{\mathrm{E}} * 1^{\mathrm{E}^{\prime} \mathrm{M}^{\prime}}$

$1^{2 \mathrm{E}} * 1^{\mathrm{M}}-1^{\mathrm{E} *} 1^{\mathrm{E}^{\prime} * 1^{\mathrm{M}}}=1^{2 \mathrm{EM}}-1^{\mathrm{E} *} 1^{\mathrm{E}^{\prime} \mathrm{M}}$

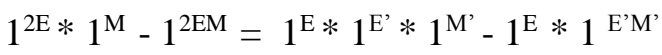

$1^{2 \mathrm{E}}\left(1^{\mathrm{M}}-1^{\mathrm{M}}\right)=1^{\mathrm{E} * 1^{\mathrm{E}^{\prime}}}\left(1^{\mathrm{M}^{\prime}}-1^{\mathrm{M}^{\prime}}\right)$ 
$1^{2 \mathrm{E}} /\left(1^{\mathrm{E}} * 1^{\mathrm{E}^{\prime}}\right)=\left(1^{\mathrm{M}^{\prime}}-1^{\mathrm{M}^{\prime}}\right) /\left(1^{\mathrm{M}}-1^{\mathrm{M}}\right)$

$1^{2 \mathrm{E}} /\left(1^{\left.\mathrm{E} * 1^{\mathrm{E}^{\prime}}\right)=0} 0^{\prime} / 0\right.$

So the end result is:

$1^{\mathrm{E}} / 1^{\mathrm{E}}=\emptyset^{+}$

$1^{\mathrm{E}} / 1^{\mathrm{E}}=0^{\prime} / 0=\emptyset^{+}$

So was the great result is:

$1^{\mathrm{E}} / 1^{\mathrm{E}},=0 \%$;

0 should therefore another new equation equation is:

$0=1^{\mathrm{E}^{\prime} * 0} / 1^{\mathrm{E}}$

It was in the calculation

$1=1+0=\left(1^{\mathrm{E}^{\prime} * 0} 0^{\prime} / 1^{\mathrm{E}}\right)+1 ;$

Calculation results of this research are:

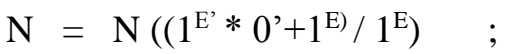

According to reference was:

$\mathrm{B} * \mathrm{D}=\mathrm{M}$;

And: $\quad \mathrm{C}=\mathrm{C}^{\prime}$;

So: $\quad E Z^{2}=C^{\prime} M$;

ie : $\quad \mathrm{Z}^{2}=\mathrm{C}^{\prime} \mathrm{M} / \mathrm{E}$

So the new theorem is as follows:

$\mathrm{Z}=$ square $\operatorname{root}\left(\left(\mathrm{C}^{\prime} * \mathrm{M}\right) / \mathrm{E}\right)$;

Alternatively there is the following relationship:

$\mathbf{C} / \mathbf{C}^{\prime}=\mathbf{Z}^{2}$

And:

$\mathbf{Z}=\mathbf{C}^{\prime} \mathbf{M} / \mathbf{E}$

So:

$\mathrm{C} / \mathrm{C}^{\prime}=\mathrm{C}^{\prime} \mathrm{M} / \mathrm{E}$;

So:

$\mathrm{C}^{\prime 2} \mathrm{M} / \mathrm{E}=\mathrm{C}$;

So the new speed of light is:

$\left(\mathrm{C}^{\prime}\right)^{2}=\mathrm{EC} / \mathrm{M}$

Final result is:

$\mathrm{C}^{\prime}=$ square $\operatorname{root}((\mathrm{E} * \mathrm{C}) / \mathrm{M})$.

This relationship explains the massive energy in the new speed of light C'.

The parameters of the relationship are as follows:

E: energy of particles found in space

$\mathrm{C}$ : the former speed of light which is known to everybody

$C^{\prime}$ : the new speed of light is $C^{\prime}>C$

M: mass of particles found in an estimated time 


\section{Acknowledgements:}

This work was supported by Mohamed daris author principal also we thank all the community of for the effort. and I would also like to thank all my university professors who have given me a lot of solid and precise information and I would also like to thank all the administrators of the community team thanks to their effort we were able to realize this document.

\section{REFERENCES}

[1] Larman DG, Rogers CA (1976) Durham Symposium on the Relations between Infnite-Dimensional and Finite-Dimensional Convexity. Bulletin of the London Mathematical Society 8: 34-37.

[2] Jonsson B, Nilsson M (2001) Transitive Closures of Regular Relations for Verifying Infnite-State Systems. International Conference on Tools andAlgorithms for the Construction and Analysis of Systems.

[3] Araki H (2004) Representations of the Canonical Commutation Relations Describing a Nonrelativistic Infnite Free Bose Gas. Journal of Mathematical Physics 4: 637

[4] Hegerfeldt GC (1972) On Canonical Commutation Relations and Infnite-Dimensional Measures. Journal of Mathematical Physics 13: 45.

[5] Hu J, Wu WZ (2012) Belief and plausibility reducts in incomplete information systems with fuzzy decision". Machine Learning and Cybernetics 1: 212-218.

Citation: Mohamed Daris, Relations of Infinite Spaces in Full Voids and Constitution of Total Energies and their Effect on Matter, International Journal of Scientific and Innovative Mathematical Research (IJSIMR), vol. 8, no. 7, pp. 1-4, 2020. Available : DOI: https://doi.org/10.20431/2347-3142.0807001

Copyright: (C) 2020 Authors. This is an open-access article distributed under the terms of the Creative Commons Attribution License, which permits unrestricted use, distribution, and reproduction in any medium, provided the original author and source are credited. 